\title{
La generación de empleo por maquiladoras en México y los ciclos económicos de Estados Unidos 1978-1985
}

Jesús H. Amozurrutia C.

El Colegio de la Frontera Norte

\begin{abstract}
Resumen
Este documento presenta y verifica un modelo explicativo de la relación entre ciclo económico en Estados Unidos y empleo en la industria maquiladora mexicana. Menciona la escasez de trabajos que estudien los mecanismos de generación de empleos en este sector, en tanto que muestra cómo la industria maquiladora ha tenido un ritmo de crecimiento mayor y más estable que la industria manufacturera durante el período de estudio. Presenta una metodología para verificación empírica de las hipótesis, estableciendo los criterios correspondientes. Los ciclos del empleo en la industria maquiladora mexicana se relacionan positivamente con el índice de producción industrial estadounidense. Entre sus conclusiones destaca que el tipo de cambio no resultó ser un factor que hubiera alentado la generación de empleos por parte de las maquiladoras.
\end{abstract}

Palabras clave: generación de empleos, maquiladoras, ciclos económicos, industria manufacturera.

\begin{abstract}
This document presents and verifies an explanatory model of relation between the economical cycle in the United States, and the employment in the Mexican maquila industry. It mentions the shortage of works researching on the mechanisms used for creation of employments in this sector, and at the same time, it shows how the maquila industry has had a faster and more stable rhythm of growth than manufacturing industry during the same period of the research. It also presents a methodology for the empirical verification of the hypothesis, and establishes the proper criteria. The employment cycle in the Mexican maquila industry is positively related to the index of American industrial production. One of the main conclusions was that the exchange rate is not an encouraging factor for the creation of employments in the maquila industry.
\end{abstract}

Keywords: creation of employment, maquila industry, economical cycles, manufacturing industry. 


\title{
LA GENERACION DE EMPLEO POR LA MAQUILADORA EN MEXICO Y LOS CICLOS ECONOMICOS DE ESTADOS UNIDOS 1978-1985
}

\author{
Por \\ Jesús H. Amozurrutia C. •
}

\section{INTRODUCCION $^{1}$}

Una de las características frecuentemente destacadade laactividad maquiladora de exportación en México es su capacidad para la generación de empleos. Sin embargo, al revisar la literatura más difundida referente a las maquiladoras, se puede observar que si bien existen estudios acerca del tipo de empleo generado por ellas, de las condiciones de trabajo y de las características de la mano de obra que se contrata, no se ha realizado ningún trabajo que especifique cuál es el mecanismo de generación de empleo por esta actividad.

Hasta ahora lo que se ha desarrollado son algunas hipótesis acerca de la relación entre el ritmo de generación de empleo por maquiladoras en México y los ciclos económicos en Estados Unidos.

Considerando lo anterior el objetivo de este trabajo es: a partir de la evaluación empírica de las hipótesis que relacionan la generación de empleos por maquiladoras en México y los ciclos económicos de Estados Unidos, diseñar un modelo económico que permita explicar el mecanismo de generación de empleo por esa actividad.

El trabajo se encuentra dividido en cinco partes; en la primera de cllas se presenta una visión descriptiva y comparativa del comportamiento del empleo generado por la industria manufacturera y la industria maquiladora en México durante el período 1978-1985, así como las hipótesis que han buscado explicar el comportamicnto del empleo en la industria maquiladora; en la segunda, sc expone la técnica empleada para verificar tales hipótesis y los resultados correspondientes; el marco teórico y el modelo explicativo de generación del empleo en la industria maquiladora se establecen en la tercera parte; la cuarta parte presenta la evidencia que permitc verificar el modelo; un resumen y las conclusiones se presentan al final.

- Investigador de el Colegio de la Frontera Norte

1 Gracias a DIMOVIFO, aunque no lo sepa y no se de cuenta, su ayuda personal fue invaluable en la realización de este trabajo. Al igual al Dr. MS por su confianza, ojalá y con esto pueda "pagarle" en algo. 


\section{DESCRIPCION E HIPOTESIS ACERCA DEL COMPORTA- MIENTO DE LA GENERACION DE EMPLEO EN LA INDUSTRIA MAQUILADORA MEXICANA 1978-1985}

\section{Evolución del empleo en la industria maquiladora y manufacturera en México.}

El dinamismo de la generación de empleos por la industria maquiladora se puede ver claramente al compararlo con la generación de empleo por la industria manufacturera.

La figura 1 mucstra los valores de la variable personal ocupado promedio en la industria maquiladora, el período considerado es de enero de 1978 a septiembre de 1985 , los números del 1 al 12 indican los meses del año correspondiente iniciando con enero ${ }^{2}$.

Siendo cautelosos con las escalas de la gráfica, se puede observar que la tendencia de enero de 1978 a octubre de 1981 es en general ascendente, con leves descensos a principios de cada año; durante noviembre de 1981 a diciembre de 1982 la variable tiende a disminuir y posteriormente inicia un marcado ascenso hasta agosto de 1984, luego un descenso de septiembre de 1984 a marzo de 1985 y por último una nueva tendencia a ascender.

La figura 2 presenta el personal acupado promedio en la industria manufacturera durante el mismo periodo. Se puede ver que el comportamiento es completamente diferente, ya que en esta industria se da un ascenso de enero de 1978 a marzo de 1982 con algunos meses en que disminuye; posteriormente, aparece un descenso en el personal ocupado que abarca de abril de 1982 a diciembre de 1983 con varios meses de crecimiento, para continuar una fase de incremento a un menor ritmo y con algunos meses de disminución.

2 Las figuras, procedimientos estadísticos y econométricos, se realizaron en el centro de cómputo de la Facultad de Economía de la Universidad Autónoma de Nuevo León. Es importante mencionarque los procedimientos para captar la variable personal ocupado promedio son diferentes según la industria de que se trate. En el caso de la industria manufacturera los datos los recopila INEGI-SPP a partir de un cierto marco muestral, para ver detalles consultar las publicaciones de INEGI-SPP, Boletín Mensual de Información Económica y la Encuesta Industrial Mensual en cualquier número. En el caso de la industria maquiladora los datos son tipo censo, ya que todas las empresas maquiladoras en México, mes a mes presentan un reporte a SECOFI el cual capta diversas variables, entre ellas el personal ocupado; posteriormente los datos son pasados de SECOFI a INEGI-SPP para su publicación. Lo anterior fue informado por el Lic. Carlos Figueroa, responsable de la oficina de INEGI-SPP en H. Matamoros, Tamps., aún con esto es posible hacer una descripción comparativa. 


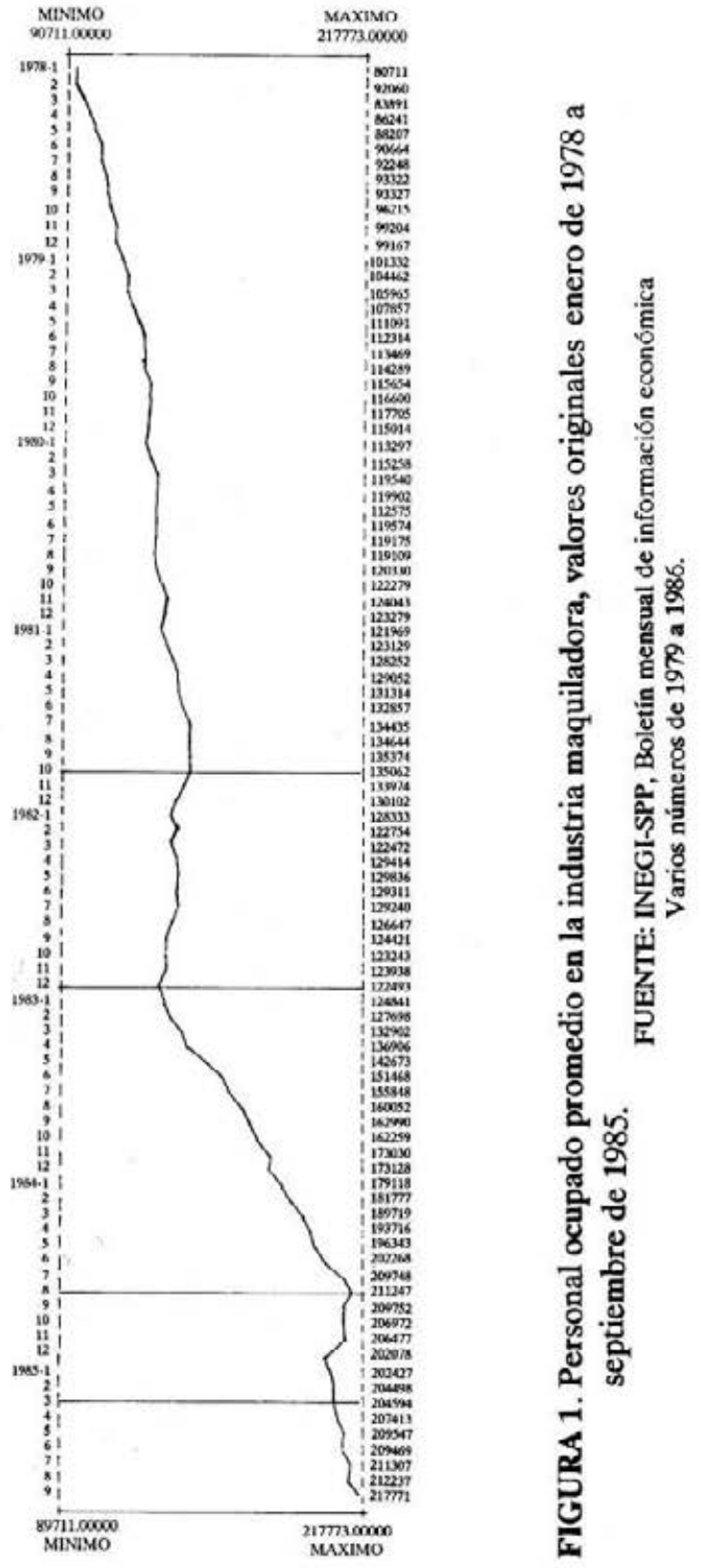




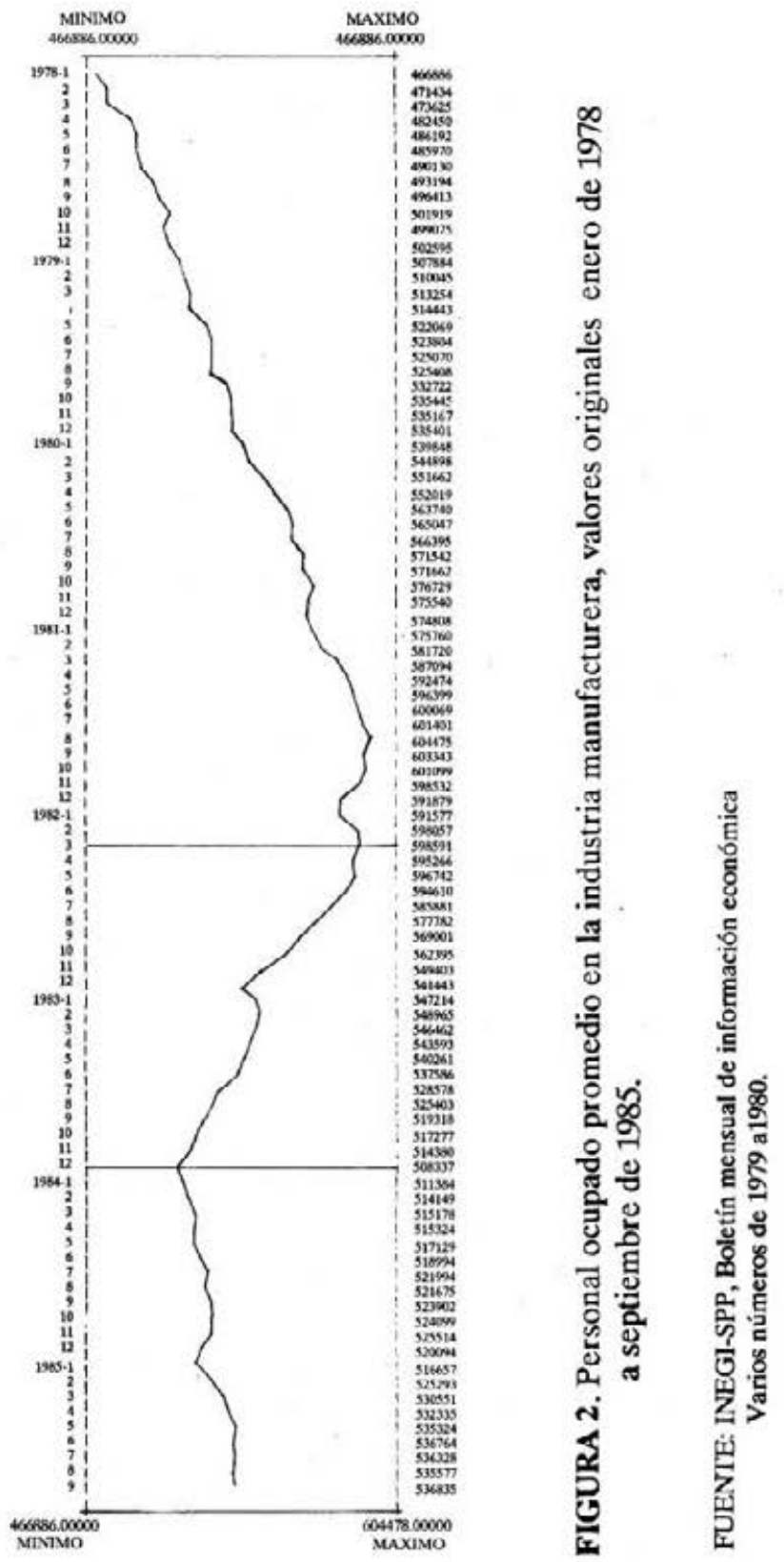


Al comparar el comportamiento del personal ocupado promediode cada una de las industrias, se puede concluir que la generación de empleo ha sido más dinámica en la actividad maquiladora que en la actividad manufacturera; además, debido a sus tendencias, se puede afirmar que los dos tipos de empleo considerados no se pueden explicar de la misma manera.

El cuadro 1 presenta algunas medidas descriptivas de la tasa de crecimiento mensual durante el período para las variables mencionadas.

\section{CUADRO 1}

Medidas descriptivas de las tasas de crecimiento mensual del personal ocupado promedio empleado en la industria manufacturera y maquiladora en México, periodo 1978:2-1985:9 ${ }^{3}$.

Industria Promedio Desviación Mínimo Máximo Coeficiente
estandar

\begin{tabular}{lccccc}
\hline Manufacturera & .16 & .81 & -2.31 & 1.86 & 5.20 \\
Maquiladora & 1.10 & 1.66 & -3.07 & 6.16 & 1.51 \\
\hline
\end{tabular}

De acuerdo con estos valores, el promedio de crecimiento de la industria maquiladora es poco más de seis veces superior que el de la manufacturera, y la variación relativa de la manufacturera es tres veces mayor que la industria maquiladora. Lo anterior indica que la industria maquiladora ha tenido un ritmo de crecimiento mayor y más estable en relación a la industria manufacturera durante el periodo considerado.

En base a las figuras y medidas descriptivas anteriores la pregunta a plantear es: $\measuredangle \mathrm{A}$ qué factores responde lageneración de empleos por la industria maquiladora mexicana?

${ }^{3}$ Los valores de las medidas descriptivas se redondearon a dos dígitos. La tasa de crecimiento se calculó según $(\underline{\mathrm{Xt}-\mathrm{X} \mathrm{t}-1}) \cdot 100$

$$
\mathrm{Xt}-1
$$

El coeficiente de variación se obtuvo dividiendo la desviación estándar de la variable entre el promedio de la misma, de esta manera la variabilidad de las series es comparable. 


\section{Hipótesis}

Esta preocupación ya existía en 1974-1975 durante lo que se conoce como el período de "crisis de las maquiladoras", en aquel entonces un funcionario de la Secretaría de Industria y Comercio, hoy Secretaría de Comercio y Fomento Industrial (SECOFI), decía: "aún no se analiza en qué medida los presentes problemas de la maquila provienen de la recesión norteamericana o de otras causas. Este análisis es muy importante para nosotros porque tenemos que saber si son problemas de costos o de demanda. Creo, además, que debemos buscar nuevos conceptos para las maquiladoras, a fin de poder resolver con mayor rapidez y agilidad sus problemas ya sea en forma global o individual". (Revista Expansión No.16,1975:58).

En enero de 1981 G. Teutli afirmaba al respecto "se constata así que las maquiladoras crecieron abundantemente. Esto no quiere decir que lo hagan siempre; por ahora el ejemplo de 1974 y 1975, en donde hubo unarecesión que afectón negativamente al sector, nose reprodujo en 19781985 , quizá porque la recesión no fue suficiente o igualmente fuerte, o quizá porque el tipo de maquiladoras ha cambiado estructuralmente y esta tendencia a internalizar los procesos es cada vez más sólida a nivel mundial" (Teutli, 1982:202-205).

Al mismo tiempo Mario de la Cabada planteaba: "En ese instante nos empieza a afectar a nosotros en la frontera o en la industria maquiladora nacional el ensamble de partes para la industria automotriz, pero sin embargo sucede un fenómeno, en el momento de que hay una recesion, y no hay dinero suficiente para comprar un autombvil, el consumidor norteamericano empieza a comprar otros antículos que no son de consumo duradero, es decir, que son de consumo inmediato, como es la ropa, y creo que ese fenómeno se ha visto reflejado en las cantidades de exportación durante la recesión de Estados Unidos;..."

J. Grunwald y K. Flamm (1983:2136) en noviembre de 1981 informan lo siguiente: "la recesión norteamericana afectó las armadoras de productos eléctricos y electrónicos en algunas partes de la región fronteriza, pero un examen más detenido revela que la baja de la producción y el empleo en otros sectores y lugares no parece relacionada con el ciclo económico de los Estados Unidos."

El planteamiento de J. Carrillo (1982:12 y 20) en diciembre de 1982, es en el sentido de que la estrecha vinculación que se ha establecido entre filial-subsidiaria y filial-matriz, tomando en cuenta que son 
diversos momentos de la misma producción, ha tenido un impacto negativo en el empleo, ya que en épocas de crisis económicas en Estados Unidos, representa un desempleo masivo en el lado mexicano." Más adelante se dice: "la constatación de que existe una dependencia directa y proporcional de la industria maquiladora a los ciclos de crisis en Estados Unidos, no será posible medir porque perdieron visibilidad los cierres y despidos ante la presente situación cambiaria". "El mayor número de personas que pueden ser contratadas con los mismos dólares ha dado un giro positivo a la maquiladora".

En agosto de 1983 Tamayo y Fernández (1983:173) opinan: "la segunda consideración, sc relaciona con la vulnerabilidad de la industria maquiladora ante fluctuaciones cíclicas de la demanda, y frente a la competencia relativa de otras zonas o países maquiladores. Esta industria al estar orientada a la exportación y ligada a un único mercado, resulta especialmente sensible a las fluctuaciones del ciclo económico estadounidense. En la recesión de 1974-1975, el nivel de ocupación se redujo en casi 9000 personas, lo que en términos relativos significó $11.5 \%$ del personal ocupado promedio en 1974".

De nuevo J. Carrillo (1985:17) en 1985 plantea: "Se considera por el contrario, que la mayoría de los cierres se deben en primer lugar a que las empresas deciden trasladarse a otros lugares en busca de mejores condiciones de rentabilidad y, en menor medida, a que las empresas en Estados Unidos van a la quicbra económica. Estos dos tipos de cierre son los más claros de seguir si se observan detenidamente los periodos de crisis economica estadounidense. De aht es posible deducir que existe una estrecha dependencia entre la industria maquiladora en México y las fluctuaciones económicas en Estados Unidos, cuya crisis de 1974-1975 por ejemplo, trajo como consecuencia el desempleo de más de 34 mil trabajadores a lo largo de la frontera mexicana y el cierre de decenas de fábricas. A pesar de que la devaluación del peso mexicano hizo más competitiva la mano de obra de ese país, durante el período 1981-1982, la industria maquiladora descendio en el empleo en $\mathbf{- 2 . 9 \%}$, al pasar de 130,973 empleados a 127,048 ". 4

Se debe mencionar que J. Carrillo (1985:17-18,50-51) verifica su hipotesis comparando gráficamente el f́ndice de producción industrial, tomando los datos y utilizando el mismo procedimiento que se plantea

\footnotetext{
${ }^{4}$ El subrayado no es del original.
} 
en un estudio publicado por Desarrollo Económico del Estado de Chihuahua, A.C.(Véase: Imagen de la industria maquiladora No.2 1985).

Tomando en cuenta los anteriores planteamientos, así como la información que actualmente existe acerca de las empresas maquiladoras mexicanas y la actividad económica en Estados Unidos, la pregunta relevante es: ¿Cuál es el apoyo empírico de las hipótesis anteriores?

CICLOS ECONOMICOS EN ESTADOS UNIDOS Y EMPLEO EN LAS MAQUILADORAS MEXICANAS: LA EVIDENCIA EMPIRICA RECIENTE.

La metodología a utilizar para la verificación empírica de las hipótesis planteadas será la siguiente:

1. Establecer, según sea la hipótesis, las variables relevantes para el estudio de la relación ciclos económicos de Estados Unidosindustria maquiladora mexicana.

2.-Definir el procedimiento de cálculo estadístico de tal relación.

3. Confrontar los resultados con los planteamientos iniciales.

Respecto a las hipótesis acerca de la relación directa entre ciclos económicos de Estados Unidos y la generación de empleos en las maquiladoras mexicanas (Carrillo, Tamayo-Fernández, 1983) así como la intensidad de los periodos de auge o crisis (Teutli, 1982), se empleará el personal ocupado promedio en la industria maquiladora mexicana, y elíndice de producción industrial en Estados Unidos, este último se puede considerar apropiado ya que se le ha tomado como coincidente con los ciclos de la actividad económica en general de los Estados Unidos (Boletín de Indicadores Económicos Internacional, 1982:73).

El procedimiento a emplear será calcular las fluctuaciones cíclicas de las variables mencionadas y la correlación que existe entre ellas, la técnica es similar a la de Hodrick-Prescott (1978) y consiste en lo siguiente:

1. Obtener el logaritmo natural de la variable y eliminar los factores de tendencia y estacionalidad, lo cual se hace por medio de la estimación de una tendencia polinominal con variables dummy. 
2. Calcular la diferencia entre los valores observados y los estimados, el resultado es una scric que contiene los movimientos cíclicos y alcatorios de la variable cn cuestión.

3. Calcular el cocficiente de correlación entre las serics que representan los movimicntos cíclicos y alcatorios, así como la desviación estándar de cada una de cllas.

4. De acuerdo a los resultados que se obtengan se establece: un coeficiente de correlación positivo implicará que la seric sca procíclica; si se obtiene un valor negativo será contracíclica ${ }^{5}$.

La desviación estándar de las series nos indica la amplitud de los ciclos.

Los criterios para no rechazar las ecuaciones de tendencia fueron:

No se rechaza aquella ccuación estimada de tendencia que generó el $\mathbf{R}^{2}$ y $\mathbf{R}^{-2}$ más altos, y que todos los coeficientes de tendencia sean significativos a un $t \alpha / 2=.025$ con grados de libertad mayor que 60 .

No se elimina la autocorrelación de los errores, ya que ésta es la que permite visualizar los movimientos ć́clicos de las variables (Gujarati,1981:216).

Los resultados obtenidos se muestran en la figura 3 , en la cual RPOPMAQ graficado con $\mathrm{M}$, es la serie ajustada estacionalmente y sin tendencia del logaritmo natural de los valores del personal ocupado promedio, RIPIEUA es la serie ajustada estacionalmente y sin tendencia del logaritmo natural del índice de producción industrial de Estados Unidos base 1980 =100, graficada con $I$.

Si comparamos el comportamiento de RIPIEUA con los valores de la variación porcentual anual del Producto Nacional Bruto (PNB) real en Estados Unidos de 1979 a 1985, datos tomados del Banco Mundial e incluidos en la gráfica, se podrá observar que existe coherencia entre estas dos variables, así: en 1979 se registra una etapa de expansión en la producción industrial así como un crecimiento de 3.2 en el PNB real, durante 1980 disminuye el ritmo del PNB real a un valor de -0.2 y la producción industrial refleja una contracción; el año de 1981 muestra una fase de expansión de la producción industrial así como una tasa de -2.1, en el año de 1983 se da una

${ }^{5}$ Se debe recordar que correlación tiene un significado diferente al de causalidad y de regresión. 


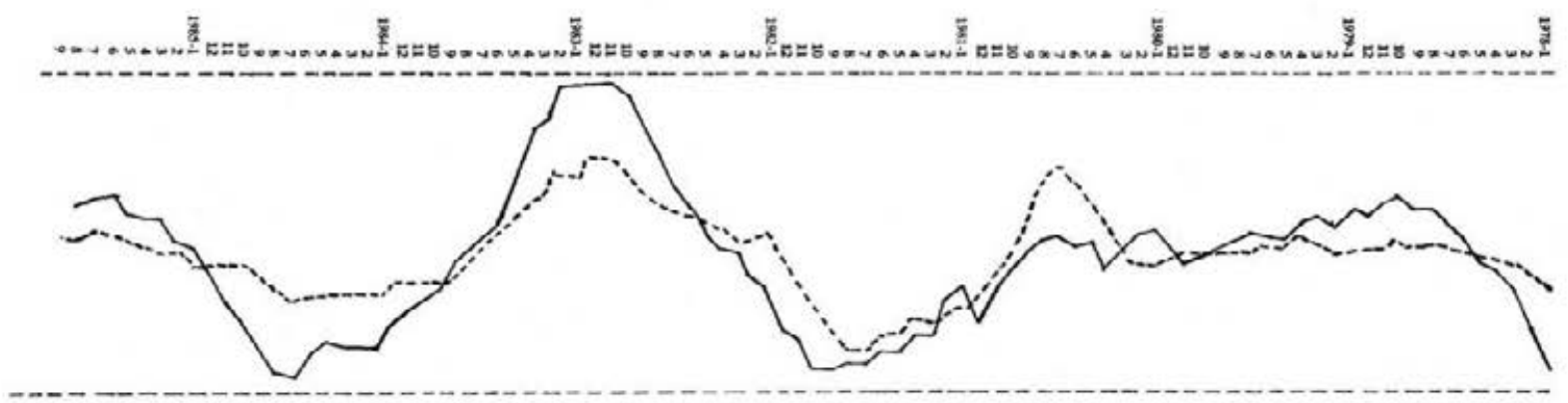

FIGURA 3. Fluctuaciones ć́clicas del personal ocupado promedio en la industria maquiladora mexicana y del indice de producción industrial de Estados Unidos. Base 1980 = 100, período 1978: 1-1985:9

RPGPMAQ graficado con ___ (Personal ocupado promedio en la industria maquiladora mexicana).

RIPIEUA graficado con -....- (Indice de producción industrial de Estados Unidos).

FUENTE: Elaborada en base a datos de: INEGI-SPP, Boletín Mensual

đe información económica. Varios números 1979-1986

ESTADOS UNIDOS

FMI. International Financial Statistics. Vrios números.

Variación Porcentual Anual del Producto Nacional Bruto Real.

FUENTE: Banco Mundial Informe sobre el Desarrollo Mundial 1986.

$\begin{array}{cccc}\text { AÑO } & \text { A\% } & \text { AÑo } & \text { A\% } \\ 1979 & 3.2 & & \\ 1980 & -0.2 & 1983 & 3.7 \\ 1981 & 3.4 & 1984 & 5.2 \\ 1982 & -2.1 & 1985 & 2.5\end{array}$


expansión en la producción y un incremento de $3.7 \mathrm{en}$ el PNB real parecido a 1983, en 1984 se crece a una tasa de 5.2 en el caso del PNB real y la producción industrial continúa en una fase de expansión, finalmente en 1985 presenta un menor ritmo de crecimiento del PNB real siendo de 2.5 así como una fase de contracción en la producción industrial. Estas relaciones inducen a afirmar que el procedimiento de cálculo en las fluctuaciones cíclicas es válido.

La figura y el coeficiente de correlación, 85 (positivo), permiten afirmar que los ciclos del empleo en la industria maquiladora mexicana están relacionados procíclicamente con el índice de producción industrial de Estados Unidos, como proxy a la actividad económica general de ese país, durante el período 1978:1- 1985:9.

En base a los valores de las desviaciones estándar de las variables, de .05 para el empleo y .03 para el índice de producción, se puede decir que los ciclos de empleo en maquiladoras son más amplios que los ciclos del índice de producción, esto también es fácil verlo en la gráfica.

Lo anterior muestra, de acuerdo a los datos y procedimiento utilizado, cómo la evidencia estadística es acorde con los planteamientos de Carrillo, Tamayo-Fernández.

En relación al planteamiento de Teutli, se puede decir que el empleo en la maquila durante el periodo 1978:1-1985:9 fue siempre procíclicorespecto a la actividad industrial en Estados Unidos. Además los ciclos del empleo siempre fueron más amplios que los de laactividad industrial, independientemente de la intensidad durante la fase de expansión o contracción.

Para la hipótesis de M. de la Cabada se emplearon los índices de producción de: bienes duraderos de Estados Unidos base 1978=100, producción industrial general base $1980=100$ y personal ocupadopromedio en la industria maquiladora mexicana ${ }^{6}$.

El procedimiento fue el ya descrito y los resultados se presentan en el cuadro 2. De acuerdo a la información, metodología y resultados, se observa lo siguiente: los ciclos del empleo durante 1978:11985:9 estuvieron más correlacionados al comportamiento de la producción de bienes duraderos que a los no duraderos, el empleo es procíclico respecto a todos los índices mencionados, la amplitud del

\footnotetext{
${ }^{6}$ Aunque los años base de los índices de bienes duraderos y noduraderos respecto al índice de producciòn general son diferentes, en este casoello no implica problemas para el cálculo de las correlaciones. El cuadro 2 redondea los valores a dos dígitos.
} 
ciclo de bienes duraderos es mayor respecto a los bienes no duraderos y que la del índice general de producción, los ciclos del empleo tienen la mayor amplitud, los ciclos de bienes no duraderos tienen la menor amplitud.

\section{CUADRO 2}

Fluctuaciones cíclicas y aleatorias de: POPMAQ, IPIEUA, IDUS e INDUS. Período 1978:1-1985:9.

\begin{tabular}{cc}
\hline Variable Desviación Estandar & $\begin{array}{c}\text { Correlación } \\
\text { con POPMAQ }\end{array}$ \\
\hline
\end{tabular}

\begin{tabular}{lcc}
\hline POPMAQ & .05 & 1 \\
IPIEUA & .03 & .85 \\
IDUS & .04 & .82 \\
INDUS & .02 & .72
\end{tabular}

POPMAQ $=$ Personal ocupado promedio de la industria maquiladora Mexicana. (Fuente: Boletín Mensual de Información Económica. INEGII-SPP).

IPIEUA = Indice de producción industrial general de Estados Unidos (Fuente: International Financial Statistics.

FMI, varios números, base $1980=100$ ).

IDUS = Indice de producción de bienes duraderos (Fuente: Survey of Current Business U.S. Dept. of Commerce/Burcau of Economic Analysis, varios números. Base: $1987=100$ ).

INDUS = Indice de producción de bienes noduraderos (para este cálculo se utilizó la misma fuente de IDUS).

En lo que a empleo corresponde, estos resultados nos indican que efectivamente la actividad maquiladora mexicana reacciona de diferentes maneras, según sea el tipo de bien que se trate.En cuanto a la hipotesis de Grunwald y Flamm, de acuerdo con la informacion disponible, es difícil establecer un procedimiento válido y consistente, lo anterior es debido a la forma en que se presenta y se calcula la informacion respecto al personal ocupado promedio en maquiladoras. Asíse tiene que el boletín mensual de información económica INEGISPP presenta esa variable en forma mensual y para toda la industria, mientras que la publicacion Estadística de la Industria Maquiladora de Exportación 1975-1983 INEGI-SPP presenta los valores en forma 
anual, calculando éstos como el promedio anual del personal ocupado promedio por rama de actividad, lo cual implica que en determinado momento ciertos movimientos de expansión o contratación (en base a la información mensual) se vean suavizados debido al uso del promedio anual.

Teniendo en cuenta lo anterior, se optó por calcular las tasas de crecimiento ${ }^{7}$, por año y por cada rama de actividad del personal ocupado promedio, distinguiéndose entre municipios fronterizos y no fronterizos.

Los cuadros 3 y 4 muestran esa información para el período 19791983, se puede observar que en el año 1982 se presenta una tasa negativa, lo cual es coherente con el cálculo mensual de los ciclos presentados en la figura 3 que muestra una fase de contracción durante ese año.Los resultados se pueden resumir de la siguiente manera:

Los municipios no fronterizos muestran las tasas más altas de crecimiento durante los años de 1980 y 1981; durante el año de 1982, que es el año en que se da una contracción en la economía norteamericana, los municipios fronterizos presentan una tasa de $\mathbf{- 2 . 7 6}$, mientras que en los municipios no fronterizos se da una tasa de $-4.83 \mathrm{cn}$ el crecimiento del personal ocupado promedio, lo cual indica que la contracción de ese año influyó más en los municipios no fronterizos que en los fronterizos, en 1983 son los municipios fronterizos los que crecen más rápido.

De los municipios fronterizos la rama de construcción, reconstrucción y ensamble de equipo y transporte y sus accesorios, muestra durante 1980, 1981, 1982 y 1983 las tasas más altas de crecimiento, siendo igualada en 1982 por la rama de servicios.

Las tasas negativas altas corresponden: en 1980 al ensamble de muebles, sus accesorios y otros productos de madera y metal; en 1981 a ensamble y reparación de herramienta, equipo y sus partes, excepto eléctrico; durante 1982 el ensamble de prendas de vestir y otros productos confeccionados con textiles y otros materiales tiene la tasa negativa más alta y en 1983 es la rama de otras industrias manufactureras la de menor crecimiento.

Respecto a los municipios no fronterizos, cada año han variado las ramas que alcanzan las tasas positivas o negativas más altas de

\footnotetext{
${ }^{7}$ Las tasas de crecimiento se calculan según $\frac{\left(X_{t}-X_{t}-1\right)}{X_{t}-1} \cdot 100$
} 
CUADRO 4. Tasa de crecimiento anual del personal ocupado en la industria maquiladora mexicana en municipios fronterizos, por etapa cíclica y rama de actividad.

\section{AÑO}

ETAPA CICLICA

\section{9}

Expansion

RAMA DE ACTIVIDAD/

TASA DE CRECDMIENTO

DE PERSONAL OCUPADO

$\begin{array}{llc}\text { I } & \text { n.d } & 20.99 \\ \text { II } & \text { a.d } & 134.8 \\ \text { III } & \text { a.d } & -8.21 \\ \text { IV } & \text { n.d } & \text { n.d } \\ \text { V } & \text { n.d } & \text { n.d } \\ \text { VI } & \text { n.d } & 12.00 \\ \text { VII } & \text { n.d } & 49.28 \\ \text { VII } & \text { nd } & -55.47 \\ \text { IX } & \text { n.d } & -32.7\end{array}$

1960

1981

Expansion
1982

Expansión Contraccion
$19 \times 3$

Expansion
1984

Expansión Contraccion
1985

Coatracción

Expansion

FUENTE: Elaborado en base a datos publicados en: INEGI-SPP: Estadistica de la industria maquiladora de exportación 1975-1985.

Notas:

* Valores redondeados a dos dígitos.

n.d. No disponible.

\section{NOMENCLATURA:}

NOFRONTERA: I. Ensamble de prendas de vestir y otros productos confeccionados con textiles y otros materiales; II. Fabricación de calzado e industria del cuero; III. Ensamble de muebles, sus accesorios y otros productos de madera y metal; IV. Productos químicos; V. Construcción, reconstrucción y ensamble de equipo de transporte y sus accesorios; VI. Ensamble de maquinaria, equipo, aparatos y artículos eléctricos y electrónicos; VII. Materiales y accesorios eléctricos y electrónicos; VIII. Otras industrias manufactureras; IX. Servicios. 
CUADRO 3. Tasa de crecimiento anual del personal ocupado en la industria maquiladora mexicana en municipios fronterizos, por etapa cíclica y rama de actividad.

\begin{tabular}{|c|c|c|c|c|c|c|c|}
\hline $\begin{array}{c}\text { AÑo } \\
\text { ETAPA CICLICA }\end{array}$ & $\begin{array}{c}1979 \\
\text { Expansion }\end{array}$ & $\begin{array}{c}1980 \\
\text { Expansióa }\end{array}$ & $\begin{array}{c}1981 \\
\text { Expansion }\end{array}$ & $\begin{array}{c}1982 \\
\text { Contraccion }\end{array}$ & $\begin{array}{c}1983 \\
\text { Expansion }\end{array}$ & $\begin{array}{c}1984 \\
\text { Expansion } \\
\text { Contraccion }\end{array}$ & $\begin{array}{c}1985 \\
\text { Contracción } \\
\text { Expansión }\end{array}$ \\
\hline \multicolumn{8}{|c|}{$\begin{array}{l}\text { RAMA DE ACTIVIDAD/ } \\
\text { IASA DE CRECIMIENTO } \\
\text { DE PERSONAL OCUPADO }\end{array}$} \\
\hline 1 & n.d & -5.94 & 1284 & 2.92 & 17.30 & -7.64 & 5.82 \\
\hline II & n.d & 4.27 & 0.15 & -16.71 & 8.35 & 17.66 & 0.47 \\
\hline III & ned & -0.97 & 18.94 & 12.19 & 36.02 & 31.27 & 18.64 \\
\hline IV & n.d & 8.10 & 230 & 6.30 & 56.72 & 30.49 & 5.18 \\
\hline v & n.d & - & 0.00 & - & . & . & . \\
\hline VI & n.d & 41.01 & 42.36 & 14.13 & 63.07 & 9.04 & 3188 \\
\hline VII & n.d & 0 & .2355 & .534 & 14.09 & 4227 & $10 . \pi$ \\
\hline VII & a.d & 3.55 & 11.27 & -3.18 & 8.01 & 25.37 & -6.47 \\
\hline IX & n.d & 9.17 & 10.15 & -3.5 & 1223 & 33.28 & -8.20 \\
\hline$x$ & n.d & 1422 & -4.88 & -3.78 & 35.55 & 7.51 & 17.71 \\
\hline $\mathbf{x a}$ & n.d & 9.35 & -0.42 & -6.75 & 7.23 & 29.58 & 29.19 \\
\hline XII & n.d & 2.57 & 5.41 & 14.35 & 38.54 & 1273 & 22.47 \\
\hline
\end{tabular}

FUENTE: Elaborado en base de datos publicados en: INEGI-SPP: Estadistica de la industria maquiladora de exportación $1975-1985$.

Notas: $\quad$ Valores Redondeados a dos dígitos.

n.d. No disponible.

\section{NOMENCLATURA}

FRONTERA: I. Selección, preparación, empaque y enlatadode alimentos: II. Ensamble de prendas de vestir y otros productos confeccionados con textiles y otros materiales; III. Fabricación de calzado $c$ industria del cuero; IV. Ensamble de muebles, sus accesorios y otros prođuctos de madera y metal; V. Productos químicos; VI. Construcción, reconstrucción y ensamble de equipos de transporte y sus accesorios; VII. Ensamble y reparación de herramienta, equipo y sus partes, excepto eléctrico; VIII. Ensamble de maquinaria, equipo, aparatos y artículos eléctricos y electrónicos; IX. Materiales y accesorios eléctricos y electrónicos; X. Ensamble de juguetes y artículos deportivos; XI. Otras industrias manufactureras; XII. Servicios. 
crecimiento, así se tiene que: en 1980 la tasa positiva más alta corresponde a materiales y accesorios eléctricos y electrónicos y la tasa negativa más alta a otras industrias manufactureras; durante 1981 el crecimiento más alto es de construcción, reconstruccióny ensamble de equipo de transporte y sus accesorios, y el decremento es de materiales y accesorios eléctricos y electrónicos; en 1982 el ensamble de maquinaria, equipo, aparatos y artículos eléctricos y electrónicos obtiene el mayor crecimiento mientras que el ensamble de muebles, sus accesorios y otros productos de madera y metal son los de mayor tasa negativa; finalmente, en 1983 es precisamente la rama de ensamble de muebles, sus accesorios y otros productos de madera y metal la que crece a la máxima tasa, ubicándose la rama de servicios en el menor ritmo.

De acuerdo a estos resultados y al observar las tasas de crecimiento para las diferentes ramas durante el año de 1982, se puede afirmar que los ciclos de actividad económica de Estados Unidos afectan, aunque no por igual, a las ramas de actividad en que se divide a la industria maquiladora, yque el efecto es diferente en los municipios fronterizos respecto a los no fronterizos, siendo lo anterior acorde con el planteamiento de Grunwald y Flamm.

Resumiendo la evidencia encontrada, de acuerdo a la información sobre las variables, período y según el procedimiento estadístico utilizado, se puede decir lo siguiente:

a) El empleo en la industria maquiladora mexicana ha mantenido una alta correlación procíclica con respecto a la actividad industrial de los Estados Unidos.

b) Los ciclos del empleo en la industria maquiladora son más amplios que los de la actividad industrial, en general y por tipo de bien, de los Estados Unidos.

c) Los ciclos del empleo en la industria maquiladora se correlacionan de manera diferente según el tipo de bien, duradero o no duradero, que se trate.

d) Los ciclos de la actividad industrial de los Estados Unidos tienen diferente influencia en la industria maquiladora mexicana según la rama de actividad y su ubicación en área fronteriza o no fronteriza.

Ante estos resultados surge la siguiente pregunta: ¿Cuál es el mecanismo cconómico que puede explicar el tipo de evidencia que se ha reportado? 


\section{MARCO TEORICO Y MODELO.}

Tomando en cuenta los resultados presentados en la sección anterior y considerando que la generación de empleo es una demanda derivada de trabajo; en esta sección se presentan los supuestos y la especificación del funcionamiento de un modelo que explique, desde un enfoque de comportamiento cíclico de las variables, la generación de empleo por la industria maquiladora en México.

Es importante aclarar que como en todo modelo, éste es una representación simplificada de la realidad, y que estasimplificación es condicionada por el marco teórico que se utilice. De esta manera, algunos procesos tales como la división internacional del trabajo, internacionalización del capital, transferencia de tecnología, etc. se toman como datos.

El cuadro 5 presenta esquemáticamente las relaciones que se dan entre la industria y familias en Estados Unidos con la industria maquiladora y familias en México, dado que lo relevante en este trabajo es la generación de empleo, se han simplificado las relaciones respecto al mercado de productos.

Los supuestos en que se basa el modelo son:

1) Competencia perfecta en el mercado de productos y en el mercado de trabajo.

2) Se opera en el corto plazo; no existen rezagos, dándose un ajuste instantáneo entre las variables, y existe un perfecto conocimiento del futuro.

3) Todas las empresas que constituyen la industria de Estados Unidos tienen un avance tecnológico tal que permite dividir el proceso productivo en tres etapas; la primera que comprende el diseño y desarrollodel producto final, suscomponentes principales $y / o$ materias primas básicas, así como la organización del proceso de producción y ventas en su conjunto; la segunda,correspondiente a la elaboración de materias primas básicas $\mathrm{y} / \mathrm{o}$ componentes principales del producto final; y la tercera que abarca el ensamble de esas materias primas y/ o componentes. De tal manera que todas las empresas que forman esa industria tienen la posibilidad técnica de instalar/retirar, según sea el caso, su tercera etapa en México como otra planta, y son estas plantas 
de tercera etapa que sí se hayan instalado en México, las que constituyen la empresa maquiladora mexicana. ${ }^{8}$

4) La productividad del trabajo en la tercera etapa es igual en México que en Estados Unidos.

5) No hay libre movilidad del factor trabajo entre los países.

6) Existen diferencias al interior de cada uno de los factores capital y trabajo atendiendo a la calidad y disponibilidad de ellos, así como del tipo de utilización.

La explicación de las relaciones presentadas es la siguiente: En Estados Unidos las unidades familiares obtienen ingresos a través de la venta de servicios de los factores productivos -tierra, trabajo, capital y empresarios- a la industria y a otras actividades económicas diferentes a la industria; se ofrecen una serie de productos finales en el caso de la industria, y productos finales y servicios en el caso de las otras actividades, los cuales son demandados y consumidos por las familias, todos los gastos e ingresos son en dólares. En México las unidades familiares ofrecen a la industria maquiladora única y exclusivamente los servicios de los factores tierra y trabajo, percibiendo por ello ingresos en pesos, no consumen los artículos de esta industria, gastando sus ingresos en el mercadode productos nacional y fronterizo, comprendiendo el último la parte de México y Estados Unidos, los gastos son en pesos o dólares según sea el lugar en que se compren los artículos.

El proceso productivo del bien final que consumen las familias de Estados Unidos, como se mencionó en el supuesto 3, se divide en tres etapas ubicando las dos primeras en Estados Unidos y la tercera en México, existiendo una frontera jurídica que implica cicrtos costos en transporte, costos por importaciones y exportaciones, un tipo de cambio dado (no necesariamente fijo), y aunado a ese tipo de cambio un diferencial de salarios (influido mas no determinado por aquél) entre México y Estados Unidos.

De acuerdo con los supuestos 4,5 y 6 , las características del trabajo y capital empleados por la industria de Estados Unidos y maquiladora en México se plantean a continuación:

${ }^{8}$ Se adopta la diferencia entre plantas y empresas presentada por Tamayo y Fernández en Zonas Fronterizas (1983:131). Además, se debe recordar que de acuerdo a las fracciones arancelarias 806.20 y 807.00 de los Estados Unidos, se debe diferenciar entre ensamble y procesamiento según la fracción bajo la cual se trabajo. 
CUADRO 5. Relaciones económicas entre industria y familias en Estados Unidos con industria maquiladora y familias en México

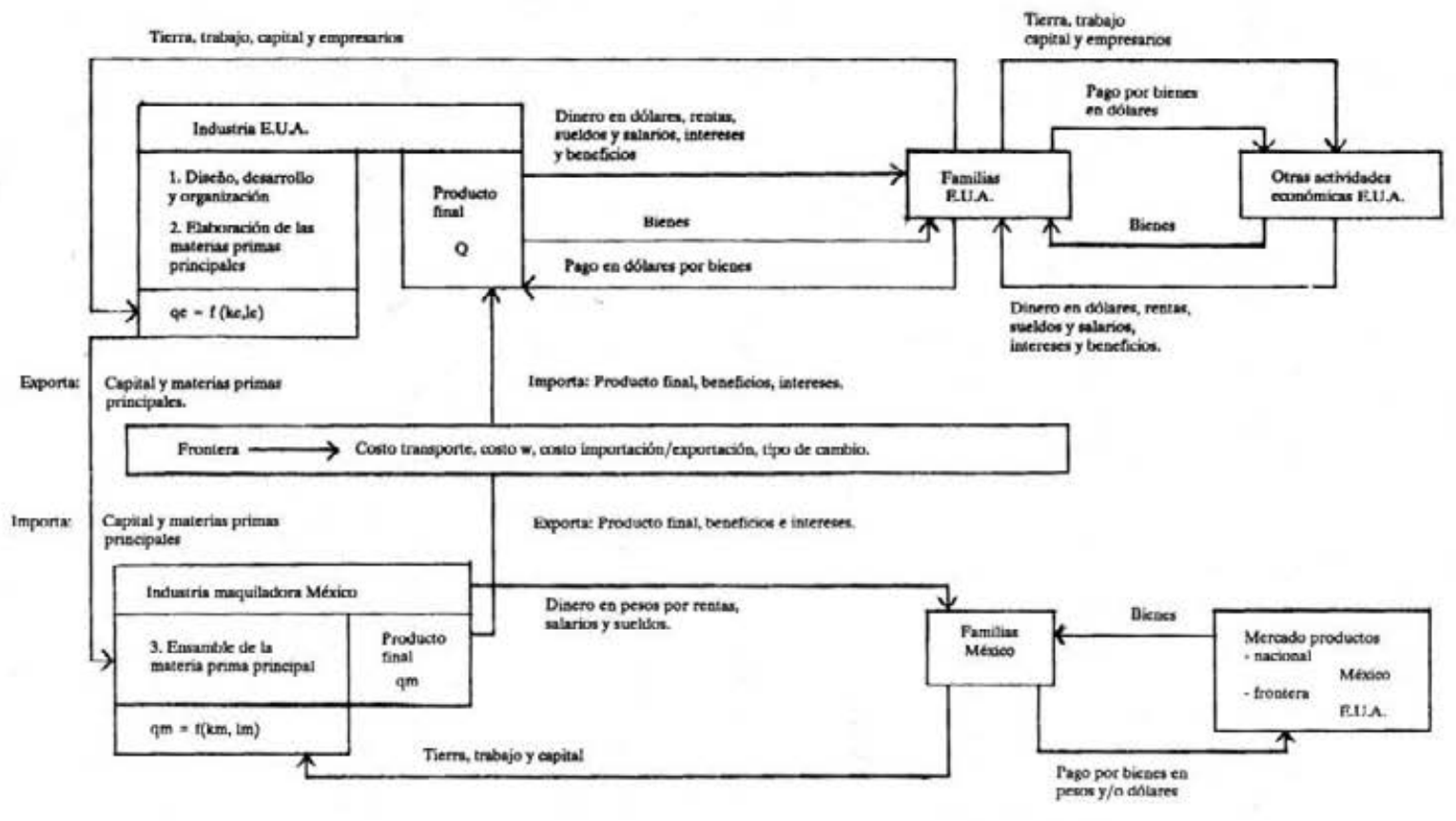




$$
\mathrm{e}=\text { Estados Unidos } \mathrm{m}=\text { México }
$$

$Q=$ producto final listo para su venta en el mercado de productos de Estados Unidos.

$\mathrm{Qe}=$ producto en Estados Unidos, que son las materias primas básicas y/o componentes principales.

$\mathrm{Qm}=$ producto en México, que es el artículo final, ya ensamblados los componentes principales y/o materias primas básicas elaboradas en Estados Unidos.

Las funciones de producción en los dos países son homogéneas de grado uno, las etapas 1 y 2 del proceso productivo que se desarrolla en Estados Unidos son intensivas en capital (más unidades de capital por unidad de trabajo) respecto a la etapa 3 que se realiza en México, siendo ésta intensiva en trabajo (más unidades de trabajo por unidad de capital) respecto a las etapas 1 y 2 en Estados Unidos.

$$
\mathrm{Qe}=\mathrm{f}(\mathrm{Ke}, \mathrm{Le}) \quad \mathrm{Qm}=\mathrm{f}(\mathrm{Km}, \mathrm{Lm}) \quad \frac{\mathrm{Ke}}{\mathrm{Le}}>\frac{\mathrm{Km}}{\mathrm{Lm}}
$$

Debido a la calidad y disponibilidad de los factores, el capital en Estados Unidos (Ke) se puede dividir en : 1) especializado, considerando el tipo de maquinaria y su tecnología, únicamente disponible en Estados Unidos, 2) no especializado, que comprende local y terrenos. En México el capital (Km) sólo es del tipo 2 no especializado, abarcando: local, terrenos y maquinaria no especializada.

En el caso de Estados Unidos el trabajo (Le) a su vez se divide en: 1) especializado, comprendiendo aquellos servicios del factor trabajo que se emplean en la etapa 1 del proceso productivo, siendo sólo disponible en Estados Unidos, y 2) no especializado, que se emplea en la etapas 2 y 3 del proceso productivo. En México el trabajo se dividirá en: 1) especializado, en organización de procesos de ensamble, y 2) no cspecializado, que se dedica al ensamble de las materias primas básicas $\mathrm{y} / \mathrm{o}$ componentes principales.

$$
\begin{array}{ll}
\mathrm{Ke}=\mathrm{f}\left(\mathrm{Ke}_{1}, \mathrm{Ke}_{2}\right) & \mathrm{Le}=\mathrm{f}\left(\mathrm{Le}_{1}, \mathrm{Le}_{2}\right) \\
\mathrm{Km}=\mathrm{f}\left(\mathrm{Km}_{1}\right) & \mathrm{Lm}=\mathrm{f}\left(\mathrm{Lm}_{1}, \mathrm{Lm}_{2}\right)
\end{array}
$$


Siendo $\mathrm{r}$ la retribución a los servicios del capital y w la retribución a los servicios del trabajo, se dan las siguientes relaciones:

$$
\text { re }>\text { rm we }>w m \quad w_{2}>w_{2} \quad w_{1}>w m_{1}
$$

Lo anterior es debido a la calidad y disponibilidad de los factores, en el caso de $\mathrm{Le}_{2} \mathrm{y} \mathrm{Lm}_{2}$ aunque su calidad sea similar lo que diferencia sus retribuciones, $\mathrm{we}_{2} \mathrm{y} \mathrm{wm}_{2}$, es la etapa y lugar en que se ubica dada la no movilidad del factor trabajo entre naciones. En el caso de México suponemos una complementaricdaden proporciones variables entre $\mathbf{L m}_{1}$ y $\mathbf{L m}_{2}$.

Las consideraciones acerca de la ccuación del costo total de una empresa típica de Estados Unidos con filial propia en México,se harán con ayuda de los siguientes símbolos:

$\begin{array}{llll}\mathrm{S}=\text { dólares } & \mathrm{p}=\text { pesos } & \mathrm{e}=\text { Estados Unidos } & \mathrm{m}=\text { México } \\ \mathrm{K}=\text { capital } & \mathrm{L}=\text { trabajo } & \mathrm{A}=\text { aduana } & \mathrm{tr}=\text { transporte } \\ \mathrm{C}=\text { costo } & \mathrm{I}=\text { importación } \mathrm{E}=\text { exportación } & \mathrm{d}=\text { distancia } \\ \text { up }=\text { unidades de producto } & \mathrm{T}=\text { total } & \end{array}$

Las unidades monetarias en que se expresan los costos, a pesar de que son diferentes en Estados Unidos (dólares) y en México (pesos), se transforman a una unidad común, en dólares, a través de dólares = pesos/tipo de cambio; de esta manera CT $=\mathrm{C} \$ \mathrm{~T}+(\mathrm{OpT} /$ tipo de cambio).

Los costos totales en dólares están en función de: los costos de capital, costos de trabajo, costos de aduanas y costos de transporte. Los costos de capital y trabajo están influidos por la cantidad y calidad de los insumos, mientras que los costos de aduanas dependen de las importaciones y exportaciones de unidades de producto, y los costos de transporte se relacionan con la distancia y las unidades de producto.

De esta manera tenemos:

Para Estados Unidos:

$$
\begin{aligned}
& \text { CT\$ }=\mathrm{f}(\mathrm{CKe}, \mathrm{CLe}, \mathrm{CAe}, \mathrm{Ctre}) \\
& \text { CKe }=\mathrm{f}\left(\mathrm{Ke}_{1}, \mathrm{Ke}_{2}\right) \\
& \text { CLe }=\mathrm{f}\left(\mathrm{Le}_{1}, \mathrm{Le}_{2}\right) \\
& \text { CAe }=\mathrm{f}(\mathrm{I}, \mathrm{E}, \text { upm }, \text { upe }) \\
& \text { Ctre }=\mathrm{f}(\mathrm{de}, \text { upe, upm })
\end{aligned}
$$


En el caso de los costos totales en la planta de México serían los mismos conceptos sólo que expresados en pesos:

$$
\begin{aligned}
& C T p=f(C K m, C L m, C A m, C T m) \\
& C K m=f\left(\mathrm{Km}_{2}\right) \\
& C L m=f\left(\mathrm{Lm}_{1}, \mathrm{Lm}_{2}\right) \\
& \text { CAm }=\mathrm{f}(\mathrm{I}, \mathrm{E}, \text { upm }, \text { upe }) \\
& \text { Ctrm }=\mathrm{f}(\mathrm{dm}, \text { upm, upe })
\end{aligned}
$$

donde upe $f$ upm ya que las unidades de producto de Estados Unidos pueden ser toneladas de cierto material, millares de piezas, etc. y las unidades de producto de México son los artículos o bienes ya ensamblados o procesados, donde el producto final en México será: los componentes principales y/o materias primas más el valor agregado por las acciones de ensamble o procesamiento.

Todo lo anterior se puede caracterizar de la siguiente forma:

Costo total de la empresa:

CTKL $=\mathrm{f}($ Tecnología de la función de producción $)$ em

$\mathrm{CTA}=\mathrm{f}(\mathrm{I}, \mathrm{E}, \mathrm{up}) \mathrm{em}$

CTtr $=f(d$, up $)$ em

dado que se está operando en el corto plazo, entonces se puede considerar que el costo de los servicios del capital en México y Estados Unidos es una constante, así la función del costo total en dólares para la empresa será:

$$
\text { CT\$ }=f(\text { CTLme, CTAme, CTtrme })
$$

en la cual el costo total de aduanas, considerando a México y Estados Unidos, yel costo total de transporte, considerando a México y Estados Unidos, se presentan como variables; el costo total del trabajo, considerando a México y Estados Unidos, es quien juega el papel fundamental, aunque en determinado momento alguno de los otros dos tipos de costo pueden tener un papel principal, pero no el fundamental.

Habiendo especificado los componentes del modelo, se presenta a continuación su funcionamiento:

Las familias en Estados Unidos maximizan su función de utilidad 
lo cual genera la curva de demanda familiar, la sumatoria horizontal de ellas nos da la demanda de mercado en Estados Unidos, siendo ésta una función de: ingreso de las familias de Estados Unidos con una relación positiva sobre la demanda de mercado, precio del bien en cuestión con relación negativa, y precio de algún(os) bien(es) alternativo(s) (sustitutos o complementarios) con relación positiva o negativa según sea el caso, así:

u (.)i = función de utilidad de la familia $\mathrm{i}$

Ii $=$ ingreso de la familia $\mathrm{i}$

qdi = cantidad demandada de la familia $\mathrm{i}$

$\mathbf{I}$ = ingreso de todas las familias

Qd = cantidad demandada en el mercado

p $=$ precio del bien

$\mathrm{pa}=$ precio de bienes alternativos

Para la familia:

$$
\begin{aligned}
& \text { maximizar } \mathrm{u}(.) \mathrm{i} \rightarrow \text { qdi }=\mathrm{f}(\mathrm{li}, \mathrm{p}, \mathrm{pa}) \\
& (+)(-)(+,-)
\end{aligned}
$$

Para el mercado:

$$
\sum_{i=1}^{\mathrm{n}} \mathrm{qdi}=\mathrm{Qd}=\underset{(+)(-)(+,-)}{\mathrm{f}(\mathrm{I}, \mathrm{p}, \mathrm{pa})}
$$

Las empresas en Estados Unidos buscan maximizar subeneficio; y ofrecen sus productos a partir de las condiciones: precio = ingreso marginal = costo marginal; $\mathrm{e}$ ingreso marginal mayor que el costo medio variable mínimo, la suma horizontal de las curvas de oferta de las empresas genera la oferta de la industria. La oferta de las empresas es una función del precio del bien que mantiene una relación positiva con ella; la tecnología que al ser económicamente viable tiene una relación positiva, y el precio de los factores de producción con relación negativa, de esta manera tenemos:

q o $\mathrm{i}=$ cantidad ofrecida por la empresa $\mathrm{i}$

$t i=$ tecnología usada por la empresa $i$

pf $=$ precio de los factores productivos para la empresa $\mathrm{i}$ 
p = precio del bien

$\mathrm{O} \mathrm{o}=$ cantidad ofrecida por la industria en el mercado

$\mathrm{T}=$ tecnología de la industria

$\mathrm{PF}=$ precio de los factores productivos en la industria

$$
\sum_{i=1}^{n} q \circ i=Q 0=f(P, T, P F)
$$

Particndo del punto de equilibrio entre las líncas de oferta y demanda de la industria en Estados Unidos supongamos:

Una disminución de la demanda originada por un decremento en el ingreso que perciben las familias, manteniendo lo demás constante, implicará un nuevo punto de equilibrio a un precio menor y una cantidad demandada menor, dado que estamos en el corto plazo. Se dará así un movimiento a lo largo de la curva de oferta de la industria, que se mantendrá constante.

La disminución de la cantidad ofrecida por la industria se hará a través de los siguientes mecanismos:

1. Disminución en el número de empresas oferentes en el mercado, debido a que el nucvo precio de equilibrio no les permite cubrir sus costos medios variables mínimos.

2. Disminución en la utilización del insumo trabajo por parte de las empresas que se mantengan en el mercado.

Las implicaciones de estos mecanismos en la generación de empleos en la industria de Estados Unidos y maquiladora en México son:

a) El número de empleos industriales en Estados Unidos y en las maquiladoras mexicanas disminuirán al retirarse del mercado empresas en Estados Unidos y cerrar sus plantas maquiladoras en México.

b) El número de empleos en la industria de Estados Unidos y en las maquiladoras mexicanas disminuirá, ya que las empresas que aún se mantengan en el mercado reducirán el uso del factor trabajo de acuerdo al siguiente proceso:

Al disminuir el precio, la empresa buscará ubicar su producción en aquel nivel que le permita cubrir, al nuevo precio, cuando menos su 
costo por la utilización al mínimo del factor trabajo.

Dadas las diferencias en calidad y disponibilidad y a las tres etapas en que se divide su proceso productivo, dejará de emplear trabajo no calificado en el proceso de ensamble (principalmente) y en elproceso de elaboración de materias primas básicas y/o componentes principales del producto final, intentando mantener la investigación y desarrollo de nuevos productos y componentes con el interés de obtener nuevos procesos productivos que le permitan disminuir costos. Al mismo tiempo tenderá a mantener en sus lugares al personal calificado en los procesos de ensamble que no se eliminen.

Lo anterior implica que, dada la intensidad en el uso del factor trabajo por la empresa maquiladora en México así como las diferentes calidades del mismo, el decremento en el empleo de trabajadores no especializados en México será mayor que los trabajadores especializados mexicanos y que los no especializados en Estados Unidos.

Esto mantiene cierta independencia del tipo de cambio ya que, a pesar de una subvaluación o devaluación del peso, ésta tendría que ser de una magnitud tal que permiticra compensar no sólo los costos en la etapa tres, sino también los costos en las demás etapas de producción de la empresa.

De esta manera, considerando las características del capital y trabajo empleados en su totalidad por la empresa, el tipo de cambio es atractivo sólo en términos de disminuir la parte de costos en el proceso de ensamble, por tanto los efectos en la disminución de costos por el tipo de cambio y sus modificaciones puede no compensar $\mathrm{cl}$ impacto de la caída en el precio por disminución de la demanda del mercado.

Hasta el momento este modelo ha podido explicarteóricamente, cuál es el mecanismo económico que relaciona la actividad económica de Estados Unidos con el empleo en la industria maquiladora mexicana.

La pregunta obligada es, ¿qué evidencia empírica lo apoya en sus implicaciones?

CICLOS DEL EMPLEO. La verificación del modelo.

Estrictamente la "mejor" forma de evaluar el modelo que se ha presentado sería el estimar, de manera simultánea, lasfunciones que 
se derivan de las relaciones planteadas en el mercado laboral y el mercado de productos, tanto para México como para Estados Unidos y establecer las relaciones entre los resultados de los países.

La limitante para hacer lo anterior es la disponibilidad de informacion respecto a ciertas variables. Debido a ello, se opto por verificar sólo algunos de los supuestos en que se basa el modelo y de las implicaciones del mismo.

Así, tenemos que en cuanto a la participación de materias primas nacionales y extranjeras en el producto final, de acuerdo a un estudio elaborado por Desarrollo Económico del Estado de Chihuahua, A. C. en noviembre de 1985, el consumo de insumos nacionales ha sido de: $1.28 \%$ en $1981,1.28 \%$ en $1982,1.30 \%$ en 1983 y $1.33 \%$ en 1984 . Lo cual muestra la importancia de los insumos extranjeros en la producción, que en esos años es de 98 y $99 \%$; las causas, de acuerdo a la encuesta a empresas maquiladoras por esta institución, son la calidad de las materias primas, la seguridad en la entrega y confiabilidad en la empresa proveedora.

La utilización intensiva de mano de obra por las maquiladoras mexicanas se puede verificar según sea la participación de sueldos, salarios y prestaciones dentro del valor agregado de la industria, comparado con su correspondiente en Estados Unidos, el cuadro 6 nos muestra esa participación, la cual es mayor en la industria maquiladora mexicana que en la industria de Estados Unidos, la información es tomada del artículo de Rivas. (1985).

Eldiferencial de salarios entre Méxicoy Estados Unidos se presenta en el cuadro $7 \mathrm{del}$ cual se observa que los sueldos y salarios promedio pagados a obreros y técnicos en maquiladoras mexicanas es, en mucho, inferior al pagado en la industria de Estados Unidos, la información es tomada del artículo de Rivas (1985) 9 .

9 Estos cuadros se presentan sólo como indicadores un tanto generales, ya que habría quever cómo se calcularon los valores. Loanterior es đebido a que, por ejemplo, el valor agregado para la industria maquiladora se calcula de manera diferente a la forma tradicional de cuentas nacionales, además para calcular los salarios en la industria maquiladora hay que recordar que el pago en sueldos, salarios y prestaciones sociales es un valor censal por así decirlo y el personal ocupado en sus diferentes clasificaciones, son promedios poblacionales. 
CUADRO 6. Participación porcentual de los sueldos, salarios y prestaciones dentro del valor agregado de la industria manufacturera

\begin{tabular}{lccc}
\hline \multicolumn{3}{c}{ México $^{1}$} \\
\cline { 2 - 4 } Año & $\begin{array}{c}\text { Industria } \\
\text { manufacturera }\end{array}$ & $\begin{array}{c}\text { Industria } \\
\text { maquiladora }\end{array}$ & Estados Unidos \\
\hline 1970 & 28 & - & 33 \\
1971 & 27 & - & 32 \\
1972 & 28 & - & 31 \\
1973 & 27 & - & 30 \\
1974 & 27 & - & 30 \\
1975 & 28 & 60 & 30 \\
1976 & 28 & 61 & 29 \\
1977 & 27 & 63 & 29 \\
1978 & 26 & 60 & 29 \\
1979 & 25 & 58 & 31 \\
1980 & 25 & 59 & 33 \\
1981 & 26 & 61 & 30 \\
1982 & 26 & 52 & 31 \\
1983 & - & 47 & - \\
\hline
\end{tabular}

1. SPP, Estadística industrial anual 1982 y Estadística de la industria maquiladora de exportación 1983.

${ }^{2}$. Federal Reserve Bulletin; Economic Report of President 1979, y 1984 Survey of Current Business.

CUADRO 7. Salarios medios pagados en la industria (Promedio mensual por persona ocupada, dólares)

\begin{tabular}{|c|c|c|c|c|}
\hline \multirow[b]{3}{*}{ Año } & \multicolumn{3}{|c|}{ México $^{1}$} & \multirow[b]{3}{*}{ Estados Unidos } \\
\hline & \multicolumn{2}{|c|}{ Maquiladoras } & \multirow[b]{2}{*}{ Manufacturera } & \\
\hline & Obreros & Técnicos & & \\
\hline 1970 & & & 136.1 & 533.3 \\
\hline 1971 & & & 144.0 & 569.8 \\
\hline
\end{tabular}


CUADRO 7. (continuación)

\begin{tabular}{ccccc}
\hline \multicolumn{3}{c}{ México $^{1}$} \\
\\
\cline { 2 - 3 } & \multicolumn{2}{c}{ Maquiladoras } & \\
\cline { 2 - 3 } Año & Obreros & Técnicos & Manufacturera & \\
\hline 1972 & & & 156.2 & 618.8 \\
1973 & & & 173.9 & 657.8 \\
1974 & & & 226.5 & 707.2 \\
1975 & 162.0 & 325.2 & 273.3 & 763.2 \\
1976 & 136.5 & 258.9 & 277.6 & 837.3 \\
1977 & 143.0 & 306.9 & 248.5 & 915.6 \\
1978 & 164.7 & 335.4 & 283.9 & 997.1 \\
1979 & 180.9 & 370.5 & 330.3 & 1075.8 \\
1980 & 207.6 & 452.4 & 398.9 & 1163.2 \\
1981 & 234.3 & 468.6 & 489.9 & 1278.4 \\
1982 & 105.6 & 206.1 & 335.0 & 1360.0 \\
1983 & 99.8 & 212.2 & 354.2 & 1416.5 \\
\hline
\end{tabular}

1. SPP. Estadística industrial anual 1983 y Estadística de la industria maquiladora de exportación, México, 1983. Las conversiones se calcularon a tipos de cambio promedio por año tomadas de FMI, International Financial Statistics, Washington, 1984.

${ }^{2}$. Elaborado con datos del Anuario estadístico del trabajo 1983 y 1984 , Oficina Internacional del Trabajo, Ginebra, Suiza.

Fuente: SPP

Los datos anteriores se refieren a los supuestos en que se basa el modelo, a continuación se presentan algunas de las implicaciones del modelo y su apoyo empírico.

1. Las fluctuaciones cíclicas del personal ocupado por las empresas maquiladoras difieren entre sí según el tipo de personal que se trate, se esperaría que los ciclos del personal no especializado sean más amplios que los del personal especializado.

La verificación de lo anterior se realizó por medio de la clasificación del personal ocupado promedio en personal especializado, que abarcaría a empleados y técnicos, y personal no especializado que 
comprende a obreros, hombres y mujeres.

El procedimiento para medir las fluctuaciones cíclicas fue igual al descrito en el primer apartado, los datos se tomaron del Boletín Mensual de Información INEGI-SPP; los resultados se presentan el cuadro 8 en el cual CONFIA es la variable que representa al personal especializado y OBTOT al personal no especializado, como se puede observar la amplitud del ciclo, dada por la desviación estándar, es mayor en OBTOT, de 0.6, que en CONFIA, de .03, lo cual apoya la implicación planteada.

CUADRO 8. Fluctuaciones cíclicas y aleatorias del personal ocupado promedio obrero (hombres y mujeres) de la industria maquiladora mexicana (OBTOT) y del personal ocupado promedio no obrero (técnicos y empleados) de la industria maquiladora mexicana (CONFIA)

\section{Desviación estandar}

OBTOT

CONFIA
.06

.03

Fuente: Boletín Mensual de Información Económica

INEGI-SPP varios números, período 1978:1-1985:9

2. Dado que se estáoperando en el corto plazo, si el medio principal para reducir las cantidades de productos ofrecidos al mercado es el decremento en el uso del factor trabajo, se debería esperar que las fluctuaciones cíclicas del personal ocupado scan mayores que las del número de maquiladoras instaladas. En este caso se empleó la variable número de maquiladoras instaladas (NUMAQ), los datos provienen del boletín mensual de información económica INEGI-SPP, el cálculo de los ciclos es el ya conocido, se le compara con las fluctuaciones del índice de producción industrial de Estados Unidos (RLIPIEU), las referencias de esta variable se dieron en el primer apartado.

Los resultados muestran que efectivamente la desviacion estándar, amplitud del ciclo, es menor de .01 respecto al personal ocupado promedio ya reportado que es de .05; además,aunque mantiene una relación procíclica respecto a la actividad económica de Estados Unidos, su valor de correlación es pequeño. Lo anterior se puede observar en la figura 4. 


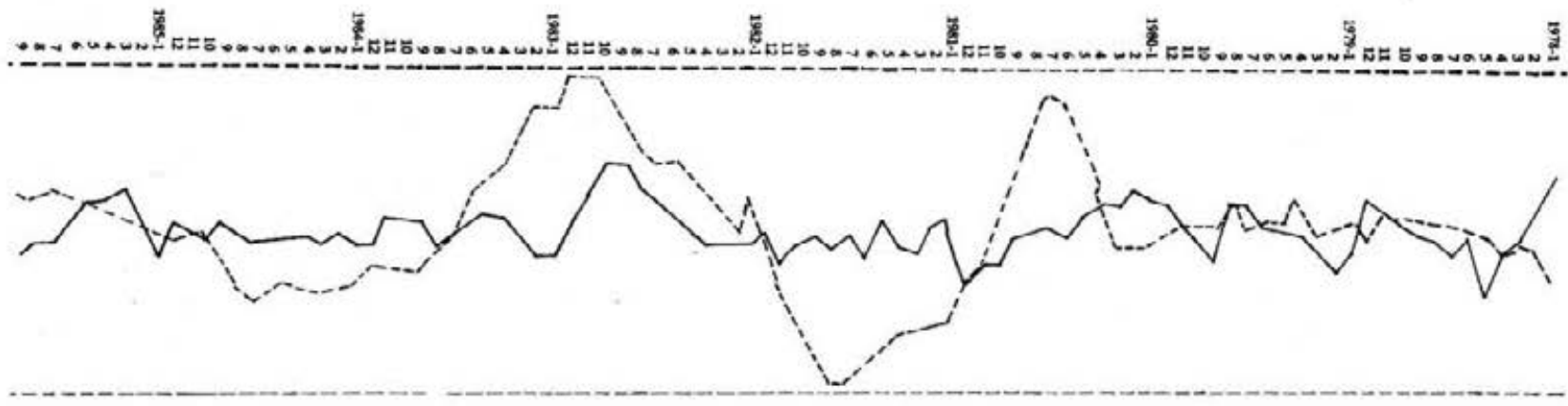

FIGURA 4. Fluctuaciones cíclicas del número de maquiladoras instaladas en México y del índice de producción de Estados Unidos período 1978: 1-1985:9.

RNUMAQ graficado con ___ (Número de maquiladoras instaladas en Méxíco.)

RLIPEAU graficado con -..... (Indice de producción industrial de E.U.A.).

FUENTE: Elaborado en base a: INEGI-SPP, Boletín mensual de información económica. Varios números, 1979-1986. FMI, International Financial Statistics. Varios númems. 
3. Atendiendo a las diferencias de calidad del factor trabajo y a la intensidad en el uso de factores entre México y Estados Unidos, se esperaría que las fluctuaciones del personal no especializado en México fucran más amplias que los del personal no especializado en Estados Unidos, además de mantener una relación procíclica.

Se utiliza la variable OBTOT ya definida para el caso de México y se define a ENSPMUS como la variable que representa a los trabajadores productivos no supervisores, que no están en el sector agrícola y trabajan en la industria de manufactura en Estados Unidos, los datos son tomados del Survey of current business. U.S. Dept. of Commerce/Bureau of EconomicAnalysis. Los resultados se presentan en la figura 5 y nos muestra una correlación procíclica de .92 entre las variables, a la vez se observa que OBTOT presenta una mayor ampliud que ENSPMUS, lo cual apoya la implicación del modelo.

4. Las modificaciones en el tipo de cambio no implican necesariamente un incremento en el empleo generado por la industria maquiladora.

La figura 6 presenta los movimientos cíclicos del empleogenerado en maquiladoras, al compararlos con los valores del tipo de cambio libre promedio al final de período ${ }^{10}$, en el cuadro 9 se observan las siguientes relaciones:

1. Durante 1978:1 - 1980:7 el empleo pasó por una fase de contracción y un leve pero sostenido periodo de expansión, el tipo de cambio mantuvo su valor casi constante.

2. De 1980:8 a 1981:10 el empleo muestra una marcada expansión y el tipo de cambio aumenta (se devalúa el peso) entre 2.50 y 3.00 unidades.

3. Se contrae el empleo durante 1981:11 y 1983:1 mientras el tipo de cambio aumenta (se devalúa el peso) de 25.67 a 98.56 unidades.

4. El empleo se expande durante 1983:2-1984:8 y el tipo de cambio varía de 98.56 a 173.70 .

5. De 1984:9 a 1985:6 vuelve a aparecer una contracción en el empleo y el tipo de cambio pasa de 177.66 a 218.56 .

Por los datos anteriores, en todo caso se puede aceptar como válida la afirmación en el sentido de que el tipo de cambio es un factor que

${ }^{10}$ De 1978:1 a 1982:12 se considera el tipo de cambio libre promedio del periodo, y de 1983:1 a 1985:9 se considera el tipo de cambio controlado promedio. Lo anterior es debido al decreto de control de cambios del 13 de diciembre de 1982, según el cual las empresas maquiladoras deben operar en el mercado controlado. 


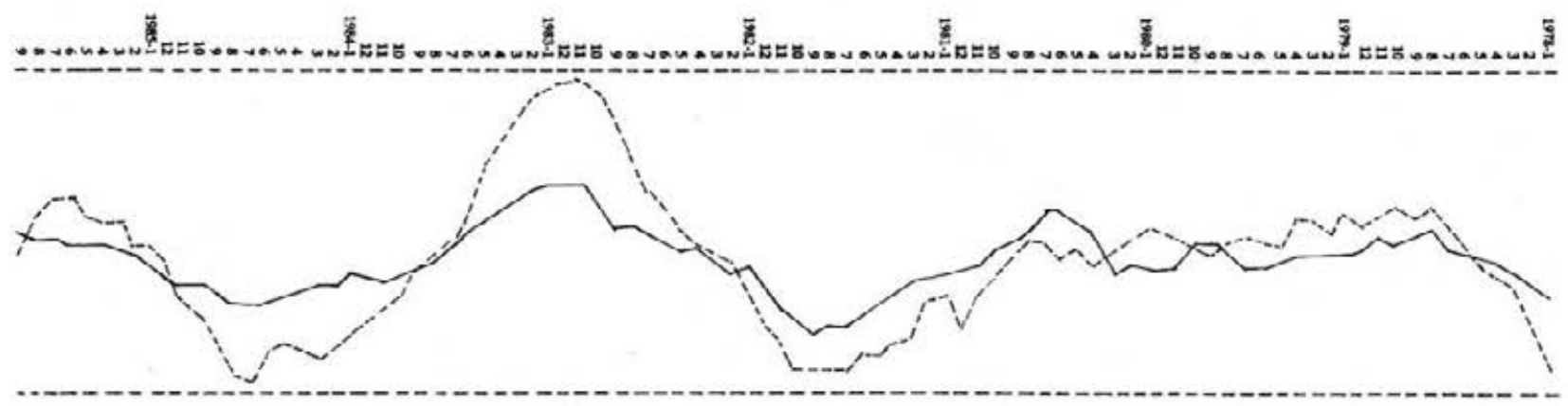

FIGURA 5. Fluctuaciones cíclicas del total de obreros (hombres y mujeres) cmpleados en la industria maquiladora mexicana y de los trabajadores productivos no supervisores, que no están en el sector agrícola y que laboran en la industria de manufactura en Estados Unidos período 1978:1-1985:9

OBTOT graficada con -.... (Total de obreros -hombres y mujeres- empleados en la industria maquladora mexicana). ENSPMUS graficado con ___ (Trabajadores productivos no supervisores que no están en el sector agrícola y que laboran en la industria de manufactura en E.U.A.).

FUENTE: Elaborado en base a información de INEGI-SPP, Boletín mensual de información económica. Varios números, 1979-1986. U.S. Department of Commerce, Survey of Current Bussiness. Varios números. 


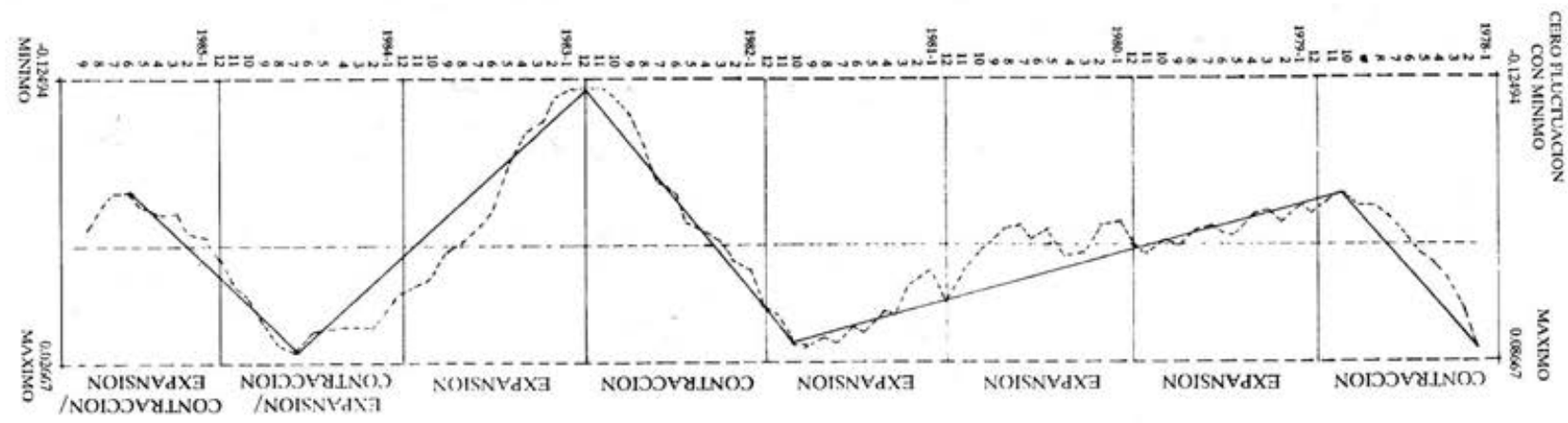

FIGURA 6. Fluctuaciones cíclicas del personal ocupado promedio en la industria maquiladora mexicana, período enero de 1978 a septiembre de 1985.

RLPOPMAQ graficada con - . . - - (Personal ocupado promedio en la industria maquiladora mexicana)

FUENTE: Elaborada en base a información de INEGI-SPP, Boletín mensual de información económica.

Varios números, 1979-1986 
estimula la generación de empleos en la industria maquiladora, siempre que ésta se encuentre en un período de expansión. Los resultados estadísticos que se han presentado, de acuerdo a la información disponible y técnica econométrica ya expuesta, permiten afirmar que este modelo es capaz de explicar el mecanismo de generación de empleos en la Industria Maquiladora Mexicana durante el período 1978:1 - 1985:9

CUADRO 9. Tipo de cambio promedio del período (TCPP)

\begin{tabular}{llllll}
\hline Año/mes & TCPP & Año/mes & TCPP & Año/mes & TCPP \\
\hline $1978: 1$ & 22.72000 & $1980: 8$ & 23.02000 & $1983: 3$ & 106.23000 \\
$1978: 2$ & 22.72000 & $1980: 9$ & 23.00000 & $1983: 4$ & 110.19000 \\
$1978: 3$ & 22.74000 & $1980: 10$ & 23.06000 & $1983: 5$ & 114.16000 \\
$1978: 4$ & 22.74000 & $1980: 11$ & 23.14000 & $1983: 6$ & 118.12000 \\
$1978: 5$ & 22.73000 & $1980: 12$ & 23.19000 & $1983: 7$ & 122.09000 \\
$1978: 6$ & 22.79000 & $1981: 1$ & 23.33000 & $1983: 8$ & 126.12000 \\
$1978: 7$ & 22.74000 & $1981: 2$ & 23.47000 & $1983: 9$ & 130.08000 \\
$1978: 8$ & 22.83000 & $1981: 3$ & 23.65000 & $1983: 10$ & 134.05000 \\
$1978: 9$ & 22.76000 & $1981: 4$ & 23.84000 & $1983: 11$ & 138.02000 \\
$1978: 10$ & 22.77000 & $1981: 5$ & 24.08000 & $1983: 12$ & 141.98000 \\
$1978: 11$ & 22.78000 & $1981: 6$ & 24.33000 & $1984: 1$ & 146.00999 \\
$1978: 12$ & 22.74000 & $1981: 7$ & 24.57000 & $1984: 2$ & 149.91000 \\
$1979: 1$ & 22.70000 & $1981: 8$ & 24.77000 & $1984: 3$ & 153.81000 \\
$1979: 2$ & 22.76000 & $1981: 9$ & 25.03000 & $1984: 4$ & 157.77000 \\
$1979: 3$ & 22.80000 & $1981: 10$ & 25.35000 & $1984: 5$ & 161.74001 \\
$1979: 4$ & 22.83000 & $1981: 11$ & 25.67000 & $1984: 6$ & 165.71001 \\
$1979: 5$ & 22.81000 & $1981: 12$ & 26.01000 & $1984: 7$ & 169.67000 \\
$1979: 6$ & 22.83000 & $1982: 1$ & 26.42000 & $1984: 8$ & 173.70000 \\
$1979: 7$ & 22.83000 & $1982: 2$ & 31.42000 & $1984: 9$ & 177.66000 \\
$1979: 8$ & 22.80000 & $1982: 3$ & 45.26000 & $1984: 10$ & 181.63000 \\
1979.9 & 22.88000 & $1982: 4$ & 45.95000 & $1984: 11$ & 185.59000 \\
$1979: 10$ & 22.81000 & $1982: 5$ & 46.77000 & $1984: 12$ & 190.02000 \\
$1979: 11$ & 22.85000 & $1982: 6$ & 47.61000 & $1985: 1$ & 195.28000 \\
$1979: 12$ & 22.81000 & $1982: 7$ & 48.49000 & $1985: 2$ & 200.28999 \\
$1980: 1$ & 22.81000 & $1982: 8$ & 83.75000 & $1985: 3$ & 205.75999 \\
$1980: 2$ & 22.81000 & $1982: 9$ & 70.00000 & $1985: 4$ & 212.14999 \\
$1980: 3$ & 22.84000 & $1982: 10$ & 70.00000 & $1985: 5$ & 218.56000 \\
$1980: 4$ & 22.82000 & $1982: 11$ & 70.00000 & $1985: 6$ & 224.96001 \\
& & & & &
\end{tabular}


CUADRO 9 (Continuación)

\begin{tabular}{llllll}
\hline Año/mes & TCPP & Año/mes & \multicolumn{1}{l}{ TCPP } & Año/mes & TCPP \\
\hline $1980: 5$ & 22.83000 & $1982: 12$ & 100.38000 & $1985: 7$ & 241.84000 \\
$1980: 6$ & 22.88000 & $1983: 1$ & 98.56000 & $1095: 8$ & 285.81000 \\
$1980: 7$ & 22.96000 & $1983: 2$ & 102.39000 & $1985: 9$ & 298.17001
\end{tabular}

Fuente: Banco de México: Series Históricas. Período enero de 1978 a septiembre de 1985.

\section{CONCLUSIONES.}

Los resultados obtenidos en este trabajo muestran cómo se da la relación entre la generación de empleos por la industria maquiladora mexicana y los ciclos de la actividad industrial en Estados Unidos, esta última como próxima a la actividad económica general.

Resumiendo los aspectos principales se puede afirmar lo siguiente:

1. La generación de empleo en las maquiladoras mexicanas mantiene una fuerte relación procíclica con la actividad industrial de Estados Unidos.

2. Atendiendo a la calidad del factor trabajo, los ciclos de empleo del personal no calificado, los obreros, tienen una mayor amplitud en sus fases de expansión o contracción respecto al personal calificado en México y al personal no calificado de Estados Unidos.

3. Los ciclos de actividad económica en Estados Unidos tienen diferente impacto en la industria maquiladora mexicana según sea la región, fronteriza- no fronteriza, y rama de actividad.

4. La generación de empleo y número de maquiladoras, aunque relacionados, se comportan de diferente manera, así los ciclos del número de maquiladorasinstaladas en México han sido menos amplios en relación a los del personal ocupado y tienen menor relación con los ciclos de la actividad industrial de Estados Unidos.

5. El tipo de cambio no es, en sí mismo, un factor que impulse la generación de empleos por las maquiladoras.

6. En general, las implicaciones del modelo muestran consistencia con las fluctuaciones cíclicas de las variables consideradas.

Existen tres comentarios respecto al enfoque y resultados de este trabajo. Primero, en el análisis de la generación de empleo no se ha considerado la relación que se mantiene entre los salarios pagados 
en México, los salarios pagados en Estados Unidos, y los salarios de otros países con industria maquiladora. Segundo, el modelo empleado y los resultados obtenidos inducen a realizar una serie de preguntas acerca de la industria maquiladora, por ejemplo: en las ciudades con empresas maquiladoras ¿Cuál es la generación de empleo por rama de actividad y cómo ha sido su comportamiento?, ¿qué importancia han tenido estas empresas en la estructura laboral de esas ciudades?, ¿durante los períodos de contracción del empleo, qué sucede con el personal que dejo de laborar en las plantas maquiladoras?, ¿de qué manera diseñar un modelo predictivo de tipo econométrico para la industria maquiladora y qué factores se deben considerar?, etc.

Por último, de acuerdo a la evidencia obtenida y desde un enfoque de protección a nuestra soberanía económica, se puede decir que si bien la industria maquiladora es tal vez la actividad industrial más dinámica en lo que a generación de empleos se refiere, también es cierto que el depender en forma principal de ella y olvidar su carácter de instrumento, muy eficaz e importante pero un instrumento al fin, nos llevaría hacia un proceso de mayor dependencia económica y política.

Aunque la economía norteamericana necesita de nosotros, es fundamental recordar que en este proceso de interdependencia asimétrica Estados Unidos no cs aún quien lleva la peor parte. 


\section{B I B L I O G R A F I A}

BANCO DE MEXICO, 1982. Boletín de indicadores económicos intemacional. Vol. VIII, No. 4 Octubre-diciembre, p. 73.

BECKER, Gary S., 1977. Teoria económica. Ed. Fondo de Cultura Económica. México.

CARRILLO, V. Jorge, 1982. "La Internacionalización del capital y la zona fronteriza México-Estados Unidos", Ponencia presentada a la North American Economics and Finance Association, New York.. Diciembre de 1982.

CARRILLO, V. Jorge, 1985. "Conflictos laborales en la industria maquiladora". Cuadernos CEFNOMEX.

FAY, A. Jon y J.L. Medoff, 1985. "Labor and output over the business cycle. Some direct evidence". American Economic Review. Septiembre de 1985, pp. 638-655.

FERGUSON, C. E. Y J. P. Gould, 1984. Teoria microeconómica. Ed. Fondo de Cultura Económica. México.

FRIEDMAN, Milton, 1982. Teoría de los precios. Ed. Alianza Universidad.

GRUNWALD, Joseph, 1983. "Reestructuración de la industria maquiladora". El trimestre económico. Vol. L (4) México, Oct Dic. 1983. No. 200 pp. 2123-2153.

GUJARATI, Damodar, 1981. Economía básica. Ed. McGraw-Hill.

HODRICK, J. Robert y Edward C. Prescott, 1978. "Post-war U. S. business cycles: A descriptive empirical investigation" versión preliminar presentado a Econometric Society: 30 de agosto de 1978.

RIVAS F., Sergio. 1985. "La industria maquiladora en México. Realidades y falacias". Comercio exterior. Vol. 35, num. 11 Nov. 1985. pp. 1071-1084

S/A , 1975. "Las interrogantes de las maquiladoras", revista Expansión 16 de abril de 1975.

SENINGER, Stephen. 1985 "Employment cycles and process renovation in regional structual change". Joumal of regional science Vol. 25, No. 2. Mayo 1985.

TAMAYO, Jesús y José L. Fernández. 1983. Zonas fronterizas (México-Estados Unidos). CIDE . Colección Estudios Políticos, Ensayo No. 2. 
TEUTLI, Guillermo. 1982. "La industria maquiladora como generadora de divisas y empleo". Conferencia publicada en $\mathrm{El}$ comercio exterior de México Tomo I. Ed. Siglo XXI. pp. 189-211.

ZELLNER, Arnold. 1980. "Philosophy and objetives of econometrics", invited association lecture for British Association of University Teachers of Economic Meeting. March 28, 1980. 